\title{
Barriers to and facilitators of colorectal cancer screening in different population subgroups in Adelaide, South Australia
}

\section{Sara Javanparast $M D, P h D$, Deputy Director, South Australian Community Health Research Unit \\ Paul R Ward \\ PhD, Professor Discipline of Public Health \\ Stacy M Carter $\mathrm{MPH}$ (Hons), $\mathrm{PhD}$ Senior Lecturer ${ }^{2}$ \\ Carlene J Wilson BA(Hons), MBA, PhD, Professor and Cancer Council South Australia Chair in Cancer Prevention (Behavioural Science) Flinders Centre for Innovation in Cancer \\ 1 Flinders University, Adelaide, SA. \\ 2 Centre for Values Ethics and Law in Medicine Sydney School of Public Health University of Sydney, Sydney, NSW. \\ sara.javanparast@ flinders.edu.au}

MJA 2012; 196: 521-523 doi: 10.5694/mjall.10701

Editorial p 490 Research p 516 olorectal cancer (CRC) is the second most common cancer and cause of cancer mortality in Australia. ${ }^{1}$ Up to $90 \%$ of CRC mortality may be preventable with early detection, indicating that the net benefit of screening is substantial. ${ }^{2}$ A National Bowel Cancer Screening Program (NBCSP) for early detection of CRC was adopted recently in Australia. ${ }^{3,4}$ Studies in Australia and overseas have shown disparity in CRC screening participation based on socioeconomic status, ${ }^{5-7}$ location, ${ }^{3,4,8}$ ethnicity, ${ }^{9-11}$ age and sex. ${ }^{12-14}$ Australian NBCSP reports found lower participation rates among men and socioeconomically disadvantaged, Indigenous and non-English-speaking populations. ${ }^{3,4,15-17}$ Although studies have investigated barriers to and enablers of screening participation, ${ }^{18-20}$ few have included different cultural groups. Guidance is needed for best practice in the development of targeted screening invitation strategies designed to address the concerns of specific groups that may be underserved. We aimed to identify and compare barriers to and facilitators of CRC screening in different cultural groups in South Australia.

\section{Methods}

We conducted a qualitative study based on interviews with people from different cultural groups in South Australia $^{21}$ between July 2009 and December 2010.

We recruited participants aged 5075 years (except for six Indigenous participants aged under 50 years) from five cultural groups: people who identified as Greek, Vietnamese or Iranian, through their response to community associations and advertisements on their local radio stations; native-English-speaking Anglo-Australians, through local newspapers; and Indigenous people from metropolitan Adelaide and rural and remote South

\begin{abstract}
Objectives: To identify barriers to and facilitators of colorectal cancer (CRC) screening participation among different cultural subgroups in South Australia, and to describe how these might be shared or be distinct across these groups.

Design, participants and setting: Qualitative study using individual interviews in Adelaide, South Australia, between July 2009 and December 2010. Participants were recruited from five culturally distinct groups in SA (Greek, Vietnamese, Iranian, Indigenous and Anglo-Australian) and included people who had participated in CRC screening and people who had not.
\end{abstract}

Main outcome measures: Factors that may act as barriers to or enablers of CRC screening.

Results: We interviewed 121 people. Members of all groups expressed positive attitudes towards cancer screening. However, we also noted a lack of knowledge about bowel cancer and its screening tests across all groups, and that the tests were viewed as unpleasant. Issues that differed across groups included language barriers, fatalistic views about cancer, embarrassment, the importance of privacy, the significance of a doctor's recommendation, moral obligations, and culture-specific concerns.

Conclusions: This study suggests that population-based screening programs may need to be modified to facilitate access and participation among minority populations and Indigenous people if equity in screening is to be achieved.

Australia, through SA Health and the Aboriginal Health Council of SA.

Interviewers explored participants' knowledge and experience of bowel cancer and screening, including barriers to and facilitators of screening. Interviews were audiorecorded and transcribed verbatim. Text was entered into NVivo, version 8 (QSR International, Southport, UK) for analysis. A coding structure was developed based on key concepts from the research questions. We also generated codes inductively to capture unexpected concepts. The same coding structure was applied across all groups to enable comparisons between groups.

Ethics committee approval was granted by the Social and Behavioural Research Ethics Committee of Flinders University and the Aboriginal Health Research and Ethics Committee of the Aboriginal Health Council of SA.

\section{Results}

We interviewed 121 men and women, 34 of whom had participated in the NBCSP (Box).

\section{Common issues related to cancer screening}

Positive attitudes

Maxims such as "prevention is better than cure" were commonly used by participants. They expressed the value of prevention as a human good, a sign of respect for God or life, a source of responsibility to act, or as economically rational. Most participants expressed the belief that cancer could be prevented by appropriate lifestyle choices.

\section{Lack of knowledge}

Only those participants who had received the test kit or had close relatives with CRC knew about CRC. Most people did not know about CRC or the NBCSP. Because of this, the arrival of a test kit made some people anxious: they erroneously believed they had been identified as being at high-risk.

Bowel cancer is something that, you know, not too many people know and talk about it. (Anglo-

Australian man, 68 years)

Unpleasant nature of test

Irrespective of their final decision on CRC screening participation, dealing with faeces was universally considered unpleasant. 


\begin{tabular}{|c|c|c|c|c|c|c|c|c|c|c|c|c|}
\hline $\begin{array}{l}\text { Cultural } \\
\text { group }\end{array}$ & No. & Men & Women & $<50$ & $50-59$ & $60-69$ & $70-75$ & $\begin{array}{l}\text { Participated } \\
\text { in NBCSP }\end{array}$ & Recruitment method & $\begin{array}{l}\text { Interviewer; } \\
\text { language of } \\
\text { interview }\end{array}$ & $\begin{array}{l}\text { Interpretation; } \\
\text { transcriber; } \\
\text { translator }\end{array}$ & Data quality check \\
\hline Iranian & 24 & 10 & 14 & 0 & 11 & 6 & 7 & 6 & $\begin{array}{l}\text { Iranian cultural } \\
\text { association, local } \\
\text { radio }\end{array}$ & $\begin{array}{c}\text { First author (S J); } \\
\text { Farsi }\end{array}$ & $\begin{array}{l}\text { nr; first author } \\
\text { [S J]; Iranian } \\
\text { national }\end{array}$ & nd \\
\hline Greek & 23 & 5 & 18 & 0 & 1 & 14 & 8 & 8 & $\begin{array}{c}\text { Greek Welfare } \\
\text { Centre, Greek radio }\end{array}$ & $\begin{array}{l}\text { First author (S J); } \\
\text { Greek }\end{array}$ & $\begin{array}{l}\text { Greek interpreter } \\
\text { also transcribed } \\
\text { and translated }\end{array}$ & $\begin{array}{l}\text { Four transcripts } \\
\text { randomly selected and } \\
\text { checked by external } \\
\text { Greek interpreter }\end{array}$ \\
\hline Vietnamese & 24 & 12 & 12 & 0 & 9 & 12 & 3 & 4 & $\begin{array}{l}\text { Vietnamese } \\
\text { community in SA }\end{array}$ & $\begin{array}{l}\text { Vietnamese man } \\
\text { and woman; } \\
\text { Vietnamese }\end{array}$ & $\begin{array}{c}\text { nr; two } \\
\text { Vietnamese } \\
\text { interviewers } \\
\text { transcribed and } \\
\text { translated }\end{array}$ & $\begin{array}{l}\text { Five transcripts } \\
\text { randomly selected and } \\
\text { checked by external } \\
\text { Vietnamese person }\end{array}$ \\
\hline $\begin{array}{l}\text { Anglo- } \\
\text { Australian }\end{array}$ & 27 & 15 & 12 & 0 & 9 & 14 & 4 & 8 & $\begin{array}{l}\text { Advertisement, } \\
\text { suburban weekly } \\
\text { newspapers, } \\
\text { metropolitan } \\
\text { Adelaide }\end{array}$ & $\begin{array}{c}\text { First author (SJ); } \\
\text { English }\end{array}$ & $\begin{array}{l}\mathrm{nr} \text {; professional } \\
\text { transcribers; not } \\
\text { required }\end{array}$ & nd \\
\hline Indigenous & 23 & 11 & 12 & 6 & 13 & 2 & 1 & 8 & $\begin{array}{c}\text { Collaboration with } \\
\text { SA Health }\end{array}$ & $\begin{array}{c}\text { Research } \\
\text { associate; English }\end{array}$ & $\begin{array}{l}\mathrm{nr} \text {; professional } \\
\text { transcribers; not } \\
\text { required }\end{array}$ & nd \\
\hline Total & 121 & 53 & 68 & 6 & 43 & 48 & 23 & 34 & & & & \\
\hline
\end{tabular}

NBCSP = National Bowel Cancer Screening Program. $\mathrm{nr}=$ not required. $\mathrm{nd}=$ not done. $*$ One Indigenous participant's age unknown.

You are dealing with a dirty part of the body .... it's why many people don't like to do it. (Greek woman, 58 years)

\section{Facilitators and barriers}

The offer of a faecal occult blood test (FOBT) kit without charge was considered to be a major facilitator of screening participation.

Common barriers to screening participation were lack of symptoms, no family history of cancer and doubt about test accuracy arising from sampling and mailing procedures.

\section{Issues that differed between groups}

\section{Language barrier}

Language barriers were a key problem for most non-English-speaking participants. Although people were willing to participate, they could not read the invitation or follow the instructions for sample collection. This delayed or prevented participation. No participants knew translations were supplied on the NBCSP website. Most participants relied on family members to assist, leading to embarrassment.

I read the instructions but it was not easy to understand. I decided to call the phone number that was provided but I did not feel comfortable either. (Iranian woman, 56 years)
English-speaking participants, in contrast, said the instructions were easy to follow.

... you read through and it's all very logical, very simple and straightforward. In 2 days you stick it in the letterbox and get the letter back in a week's time. (Anglo-Australian man, 62 years)

\section{Fatalistic views about cancer}

Most Anglo-Australians thought cancer was treatable, and that this had improved over time. However, participants from culturally and linguistically diverse (CALD) groups were more likely to avoid screening because of fear of cancer diagnosis, seeing cancer as unpreventable and fatal.

It's the forbidden disease. In the Greek community when they hear this word, it is the end of the world for them. They don't like to talk about it. (Greek woman, 69 years)

I know my grandma, for her the word "cancer" - her immediate thought would have been fear. She came from a generation that cancer was a death sentence, which is not something which it necessarily is today. (Anglo-Australian woman, 68 years)

\section{Privacy of doing the test}

For most participants, the privacy of at-home testing was valued. However some Indigenous participants used the term "shame job" to describe the FOBT. They explained that they lacked privacy in their homes, neighbourhoods and communities. In remote areas, even postal workers had intimate personal knowledge, creating potential embarrassment from mailed FOBT kits and samples.

Indigenous participants and those from CALD backgrounds - but not Anglo-Australians - said they wanted health worker support to complete the test because of perceived low self-efficacy.

\section{Doctor's recommendation}

Although all participants considered a doctor's recommendation to be encouraging to some extent owing to trust in or personal obligation to their doctors, Anglo-Australians valued physician endorsement highly and said it strongly influenced their decision to undergo screening.

If my doctor asked me to do it I would do it because I've got a lot of respect for him and he's looked after me wonderfully. (AngloAustralian woman, 61 years)

\section{Moral obligation}

The Iranian group in particular discussed a moral obligation to participate: compliance was the morally acceptable response to free preventive services offered by a government to improve individual and population health. 
A few participants from Greek and Iranian groups suggested that personal preventive health care was less important than other family health priorities in their cultures.

\section{Spiritual beliefs}

Belief in a spiritual aetiology of cancer was also suggested as a potential barrier to screening participation among Greek and Vietnamese communities. Some participants expressed the belief that health and disease and life and death were in God's hands, and so not preventable.

The Vietnamese people believe in karma, if I have got the disease that is the Gods' will ... (Vietnamese man, 58 years)

\section{Discussion}

We identified several culture-specific issues related to CRC screening among five culturally distinct groups in Adelaide. Further work is necessary to extend and replicate our findings; however, we propose several possible strategies that could be tested as means to achieving greater equity in the NBCSP.

The first is changes to public communication about cancer and screening. We found different understandings of the preventability of cancer in different groups. Media reporting of CRC in Australia has been shown to be relatively low; ${ }^{22}$ accurate reporting of preventability and screening efficacy, including social marketing about screening, could improve screening uptake. This would need to be culturally and linguistically appropriate. In this study, Englishspeakers found testing straightforward, easy and private; non-English speakers were confused, felt uncomfortable and had to talk to a family member about their faeces. Translated program documents on a website made no difference. If equitable access to screening is to be provided, language barriers must be overcome.

Our second strategy relates to the role of health professionals in screening. Consistent with many other studies, ${ }^{20,23,24}$ we found a doctor's endorsement facilitated screening participation for all participants, and especially Anglo-Australians. We hypothesise that involving health care professionals in screening using an FOBT may benefit most Australians, for different reasons. For people from CALD groups, a health professional may help with several identified barriers: language, problems with self-efficacy and confidence, and fatalistic views about cancer. Anglo-Australians valued both privacy and medical recommendation and they may prefer to receive their clinician's recommendation, then take the test home to use in private. For Indigenous Australians, testing as a "shame job" appeared to arise from the smallness and interconnectedness of communities, and being screened by health workers in such a community may contribute to this embarrassment. Indigenous community-controlled research may be needed to identify possible solutions.

The diversity we observed across participant groups suggests that a one-size-fits-all bowel cancer screening program is not equitable. Tailored approaches need to be developed to ensure equitable participation across the population.

Acknowledgements: We acknowledge SA Health for funding the project under the Strategic Health Research Program, and Medicare Australia for providing access to the data. We also thank the participants, who gave generously of their time to share their experiences with us.

Competing interests: No relevant disclosures.

Received 3 Jun 2011, accepted 29 Aug 2011.

1 Australian Institute of Health and Welfare, Australasian Association of Cancer Registries. Cancer in Australia: an overview, 2008. Canberra: AlHW, AACR, 2008. (AlHW Cat. No. CAN 42; Cancer Series No. 46.) http://www.aihw.gov.au/WorkArea/ DownloadAsset.aspx?id=6442454588 (accessed Feb 2012).

2 Smith RA, von Eschenbach AC, Wender R, et al; ACS Prostate Cancer Advisory Committee, ACS Colorectal Cancer Advisory Committee, ACS Endometrial Cancer Advisory Committee. American Cancer Society guidelines for the early detection of cancer: update of early detection guidelines for prostate, colorectal, and endometrial cancers. CA Cancer J Clin 2001; 51: 38-75.

3 Australian Institute of Health and Welfare, Department of Health and Ageing. National Bowel Cancer Screening Program: annual monitoring report 2009. Canberra: AlHW, 2009. (AlHW Cat. No. CAN 45; Cancer Series No. 49.) http://www.aihw.gov.au/ WorkArea/DownloadAsset.aspx?id=6442454613 (accessed Feb 2012)

4 Australian Institute of Health and Welfare, Department of Health and Ageing. National Bowel Cancer Screening Program monitoring report 2008. Canberra: AlHW, 2008. (AlHW Cat. No. CAN 40; Cancer Series No. 44.) http://www.aihw.gov.au/ WorkArea/DownloadAsset.aspx?id=6442454594 (accessed Feb 2012)

5 Whynes DK, Frew EJ, Manghan CM, et al. Colorectal cancer, screening and survival: the influence of socioeconomic deprivation. Public Health 2003; 117: 3 89-395.

6 McCaffery K, Wardle J, Nadel M, Atkin W. Socioeconomic variation in participation in colorectal cancer screening. J Med Screen 2002; 9: 104-108.

7 Singh SM, Paszat LF, LiC, et al. Association of socioeconomic status and receipt of colorectal cancer investigations: a population-based retrospective cohort study. CMAJ 2004; 171: 461-465.

8 Martini A, Javanparast S, Ward PR, et al. Colorectal cancer screening in rural and remote areas: analysis of the National Bowel Cancer Screening Program data for South Australia. Rural Remote Health 2011; 11: 1648.

9 UK CRC Screening Pilot Evaluation (Ethnicity) Team Ethnicity: UK Colorectal Cancer Screening Pilot, final report. London: UK Department of Health, 2003. http://www.cancerscreening.nhs.uk/bowel/ ethnicity-finalreport.pdf (accessed Feb 2012).

10 Jerant AF, Fenton JJ, Franks P. Determinants of racial/ethnic colorectal cancer screening disparities. Arch Intern Med 2008; 168: 1317-1324.

11 Goel MS, WeeCC, McCarthy EP, et al. Racial and ethnic disparities in cancer screening: the importance of foreign birth as a barrier to care. J Gen Intern Med 2003; 18: 1028-1035.

12 McGregor SE, Hilsden RJ, Li FX, et al. Low uptake of colorectal cancer screening $3 \mathrm{yr}$ after release of national recommendations for screening. Am J Gastroenterol 2007; 102: 1727-1735.

13 Ko CW, Kreter W, Baldwin LM. Persistent demographic differences in colorectal cancer screening utilization despite Medicare reimbursement. BMC Gastroenterol 2005; 5: 10.

14 Cooper GS, Doug Kou T. Underuse of colorectal cancer screening in a cohort of Medicare beneficiaries. Cancer 2008; 112: 293-299.

15 Australian Government Department of Health and Ageing. The Australian Bowel Cancer Screening Pilot Program and beyond: final evaluation report. Canberra:DoHA, 2005. http://www.health.gov.au/ internet/screening/publishing.nsf/Content/finaleval-cnt (accessed Feb 2012).

16 Javanparast SJ, Ward PR, Cole S, et al. A crosssectional analysis of participation in National Bowe Cancer Screening Program in Adelaide by age, gender and geographical location of residence. Australasian Medical Journal [internet] 2010; 1: 141-146. http://www.amj.net.au/index.php? journal=AMJ\&page=article\&op=viewFile\&path[] =198\&path[]=498 (accessed Feb 2012).

17 Ward PR, Javanparast S, Matt MA, et al. Equity of colorectal cancer screening: cross-sectional analysis of the National Bowel Cancer Screening Program data for South Australia. Aust N Z J Public Health 2011; 35:61-65.

18 Bastani R, Gallardo NV, Maxwell AE. Barriers to colorectal cancer screening among ethnically diverse high- and average-risk individuals. J Psychosoc Oncol 2001; 19: 65-84.

19 Berkowitz Z, Hawkins NA, Peipins LA, et al. Beliefs, risk perceptions, and gaps in knowledge as barriers to colorectal cancer screening in older adults. J Am Geriatr Soc 2008: 56: 307-314.

20 Brouse CH, Basch CE, Wolf RL, et al. Barriers to colorectal cancer screening with fecal occult blood testing in a predominantly minority urban population: a qualitative study. Am J Public Health 2003; 93: 1268-127.

21 Kitto SC. Chesters J, Grbich C. Quality in qualitative research: criteria for authors and assessors in the submission and assessment of qualitative research articles for the Medical Journal of Australia. Med J Aust 2008; 188: 243-246.

22 MacKenzie R, Chapman S, Johnson N, et al. The newsworthiness of cancer in Australian television news. Med J Aust 2008; 189: 155-158.

23 Cole SR, Smith A, Wilson C, et al. An advance notification letter increases participation in colorectal cancer screening. J Med Screen 2007; 14: 73-75.

24 Ward PR, Javanparast S, Wilson C. Equity of bowel cancer screening: which groups have inequitable participation and what can we do about it? Aust J Prim Health 2011; 17: 334-346. 
- Research

524 MJA $196(8) \cdot 7$ May 2012 